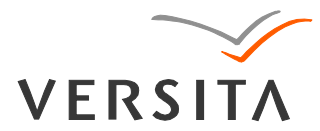

VERSITA
GEOCHRONOMETRIA 41(4) 2014: 352-360

DOI 10.2478/s13386-013-0165-y

Available online at

www.springerlink.com

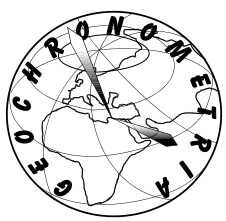

\title{
LUMINESCENCE DATING OF BRICKS FROM THE GOTHIC SAINT JAMES CHURCH IN TORUŃ
}

\author{
ALICJA CHRUŚCIŃSKA ${ }^{1}$, ANNA CICHA ${ }^{2}$, NATALIA KIJEK ${ }^{1}$, PIOTR PALCZEWSKI $^{\mathbf{1}}$, \\ KRZYSZTOF R. PRZEGIETKA ${ }^{1}$ and KRYSTYNA SULKOWSKA-TUSZYŃSKA ${ }^{2}$ \\ ${ }^{1}$ Institute of Physics, Faculty of Physics, Astronomy and Informatics, Nicolaus Copernicus University, Grudziadzka 5, 87-100 Toruń \\ ${ }^{2}$ Institute of Archaeology, Faculty of History, Nicolaus Copernicus University, Szosa Bydgoska 44/48, 87-100 Toruń
}

Received 7 October 2013

Accepted 8 May 2014

\begin{abstract}
Saint James Church in Torun is one of the most important gothic monuments in Poland. The date of the beginning of its construction is known from historical reports but the earlier history of the site remains undiscovered. During the archaeological excavations in years 2010 and 2011 five brick samples were collected for luminescence dating as well as four additional samples from the brick surroundings for the dose rate estimation. The equivalent dose was determined by TL and OSL methods. The TL results differ significantly from the OSL results but the last ones are verified by historical knowledge and radiocarbon dating. Establishing the dose rate from gamma rays needs a special attention because of the complex course of the foundations of the church. The details of the applied approach are presented in the current work. The results obtained indicate that a solid brick construction existed at the site of the presbytery of the Saint James Church before it was build.
\end{abstract}

Keywords: dating bricks, optically stimulated luminescence, thermoluminescence, annual dose.

\section{INTRODUCTION}

Bricks were one of the first objects of luminescence dating over fifty years ago (Grogler et al., 1960, Kennedy and Knopf, 1960). The investigations of this material have also an important contribution into the development of retrospective dosimetry especially during examining the consequences of the Chernobyl accident (Bailiff, 1995; Hütt et al., 1993; Bailiff et al., 2000). Brick dating, however, in comparison to pottery or geological sediment dating is rather rarely reported in literature (Goedicke et al., 1981; Bailiff, 2007; Chruścińska et al., 2008; Blain et al., 2011; Guibert et al., 2009; Blain et al., 2007; Roque et al., 2002; Roque et al., 2004; Bevilacqua et al., 1999; Martini and Sibilia, 2001). Applying the luminescence

Corresponding author: A. Chruścińska e-mail: alicja@fizyka.umk.pl method to establish the history of significant objects may make luminescence dating more popular among architecture researchers. Saint James Church in Torun is one of the most precious gothic monuments in Poland, so the dating of its brick foundations can make a valuable contribution to the dissemination of this absolute dating method among the Polish archaeologists. Regular excavations at the Saint James Church have been carried out for several years in order to investigate the remains of the church that had existed before the present seven hundredyears-old temple was build. Altogether 11 brick samples were collected in 5 excavations located by the southeastern side, northwestern side of the present presbytery and vestry. Here we present results obtained for 5 samples collected from the excavations on the northwestern side of presbytery. In the case of these samples, the places of their collection are characterized by a complex geometry 
and a heterogeneous spatial distribution of radioactivity. Hence in this work a special attention is paid to the estimation of the external gamma annual dose. The way of applying the principle of superposition is presented for each case of the complex surrounding geometry.

\section{ARCHAEOLOGICAL SITE}

The church under the vocation of St. James (Fig. 1) in the town of Torun by the Vistula River - is situated in the New Town Market Square area, where in 1264 New Town of Torun was located. Construction of the church's present body started with presbytery in 1309 , then aisles and the western part were completed (Freymuth, 1981; Kluczwajd, 2009; Cicha, 2010; Sulkowska-Tuszyńska, 2010; Krantz-Domasławska and Domasławski, 2001; Sulkowska-Tuszyńska and Cicha, 2010; SulkowskaTuszyńska, 2012). Finally all the building was encircled with chapels. Presbytery of the temple is erected on a long rectangle plan $(11.2 \times 20.6 \mathrm{~m})$ closed with a straight line from the east. The edifice appears to be exceptionally high, its interior divided in 3 rectangular, narrow bays and a larger, almost square one, on the east. Buttresses are fetched from the outside on the borderlines of the following bays at the right angle along the walls. Buttresses on the corners are set up aslant, from the North

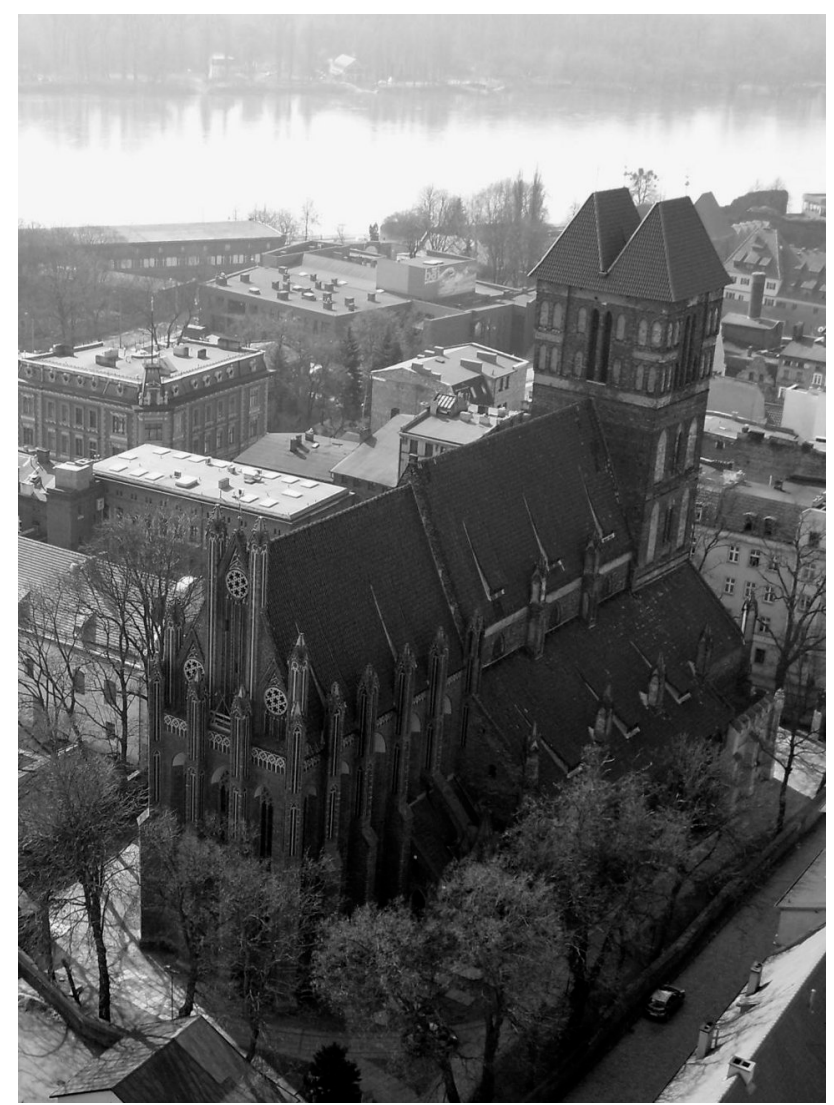

Fig. 1. Saint James Church in New Town of Toruń, Poland. and the South, two on each side (Fig. 2). Foundations of the northern presbytery buttresses will be the subject of our subsequent considerations. Exceptionally slander and imposing with proportions, the construction was made of bricks, decorated with blank windows, three rosettes in the top of eastern elevation and enriched with glazed bricks.

During short archaeological excavations lasting only 3 months (in 2008, 2010 and 2011) in addition of finding 170 graves and several building foundations around the church, we have obtained first information concerning the concept of the construction of presbytery and furnishing of its interior. And so, in trenches set next to the first and around the second eastern aslant buttress, we have discovered enormous stone foundation, 3-meter high, bound with lime mortar. This foundation had two distinct offsets - a higher one and a lower one, made of bricks. Their arrangement was in agreement with the course of foundation. We have determined that homogenous foundation under the second aslant buttress is positioned at the right angle to the axis of presbytery, and under the first one (not fully uncovered as yet) most surely at sharp angle to the axis. Both the buttresses resting on the foundation are placed slantwise to the axis. It can also be seen, that the second buttress (positioned differently from its foundation), is considerably shorter and narrower than the foundation and has no offsets (see Fig. 3).

There are then at least two possible explanations of this occurrence. First possibility is that the uncovered foundation could support another, older temple erected of bricks as early as in $13^{\text {th }}$ century, when the New Town Torun came into existence. Another explanation is the change of the initial conception by a builder who supervised the construction of the basilica in the $14^{\text {th }}$ century. He could start to build the foundation of second buttress from the East perpendicularly to the church axis but then the builder decided to change the direction of this buttress and built it obliquely to the church axis. To enable clarifi-

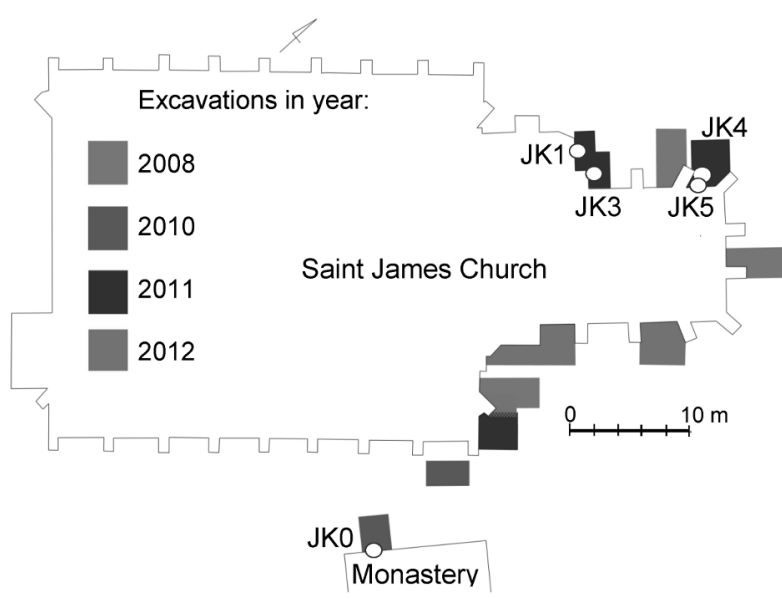

Fig. 2. The plan of the church and locations of sample collection. 
cation of these theses it would be helpful to establish the age of bricks from the foundation of the buttresses. In this paper we present results for 5 samples: JK0, JK1, JK3, JK4 and JK5, the locations of which are shown in Figs. 2, 3 and 4 . One sample (JK0) is not connected directly with the church but originates from the foundations of a monastery that is located in its vicinity. The date of establishing the monastery is not known but the date obtained by the radiocarbon dating for some organic remains found in the vicinity of the foundation is $1210-1390$ A.D.

\section{METHODS}

\section{Experimental details}

As has been mentioned above, 5 samples were collected from the excavation place. One of them (JK3) was taken by the dry drilling in the form of three cores of dimensions $\varnothing 6 \times 7 \mathrm{~cm}$, the rest of the samples were the bricks as a whole obtained by means of a hammer and chisel.

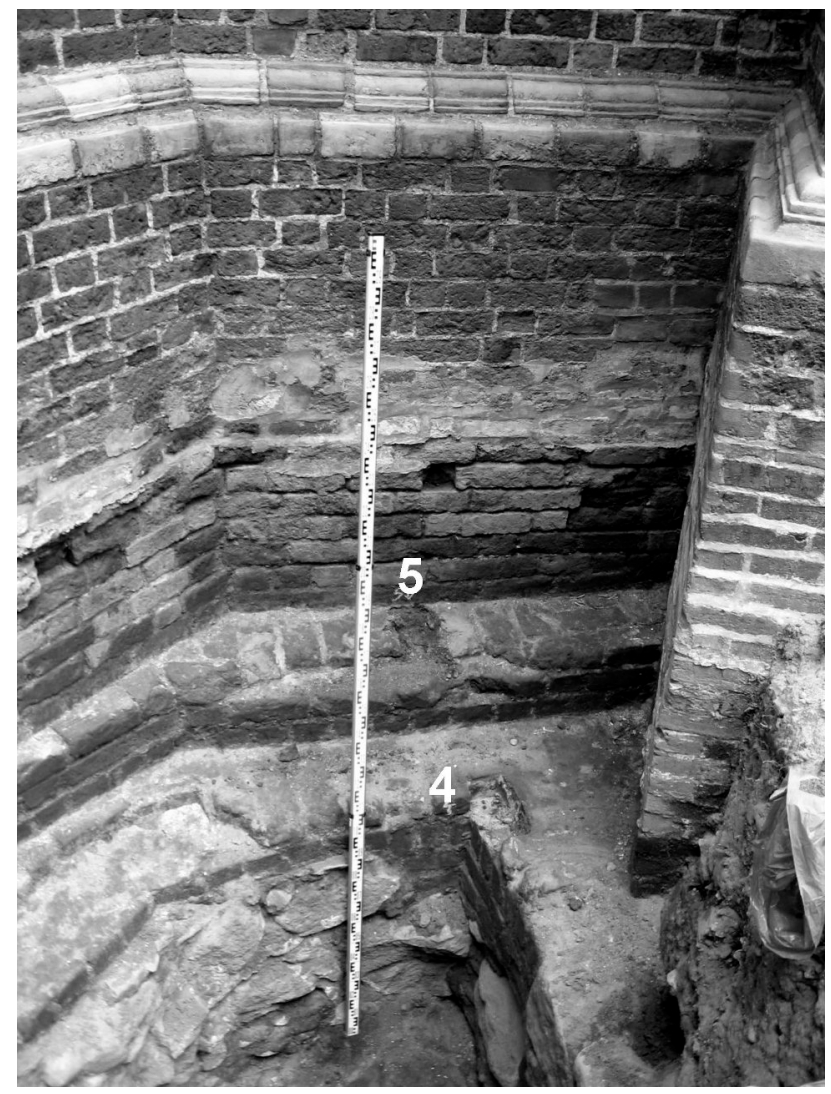

Fig. 3. The church foundations made of bricks and two their offsets whose arrangement fits to the run of a deeper stone foundation but does not agree with the way of construction of the buttresses. Places of collecting the sample JK4 and JK5 are marked in order to demonstrate the complex geometry of sample surrounding. The position of sample JK4 requires that the "3/8 brick matrix + 5/8 soil matrix" geometry had to be considered in the $y$ annual dose calculations. In the case of the sample JK5 the " $1 / 4$ brick matrix $+3 / 4$ soil matrix" geometry was considered.
In order to estimate the equivalent dose $\left(D_{\mathrm{e}}\right), 100$ $200 \mu \mathrm{m}$ diameter quartz grains, were extracted from bricks by the standard procedure including heavy liquid separation and etching in 40\% HF (Chruścińska et al., 2008). All OSL measurements were carried out using RISØ TL/OSL System TL-DA-20 equipped with a conventional Hoya U-340 filter and EMI 9235QB photomultiplier. A blue LED stimulation module $(450-550 \mathrm{~nm}$, $80 \mathrm{~mW} / \mathrm{cm}^{2}$ ) was applied as an optical stimulation source. A ${ }^{90} \mathrm{Sr} /{ }^{90} \mathrm{Y}$ source giving a dose rate of about $18 \mathrm{mGy} / \mathrm{s}$ was utilized for the OSL excitation. The TL investigations were conducted using RISØ TL/OSL System TLDA-12 equipped with a BG39 Schott filter and an EMI 9235QA photomultiplier. The annual dose that consists of the contributions from the beta and gamma radiation (during etching the alpha dose contribution was eliminated) was estimated by means of gamma spectrometry. Canberra System 100 equipped with a HPGe detector allowed measuring the radioactivity of natural isotopes present in the bricks and the surrounding soil. (Oczkowski and Przegiętka, 1998a).

\section{Equivalent dose determination}

Three methods were used in order to determine $D_{\mathrm{e}}$ (Table 1) - the single aliquot regeneration dose protocol (SAR) applied for OSL and TL signal and the TL additive dose method (with the correction for non-linearity effects). In the case of the TL measurements a plateau test was performed in order to establish the temperature range

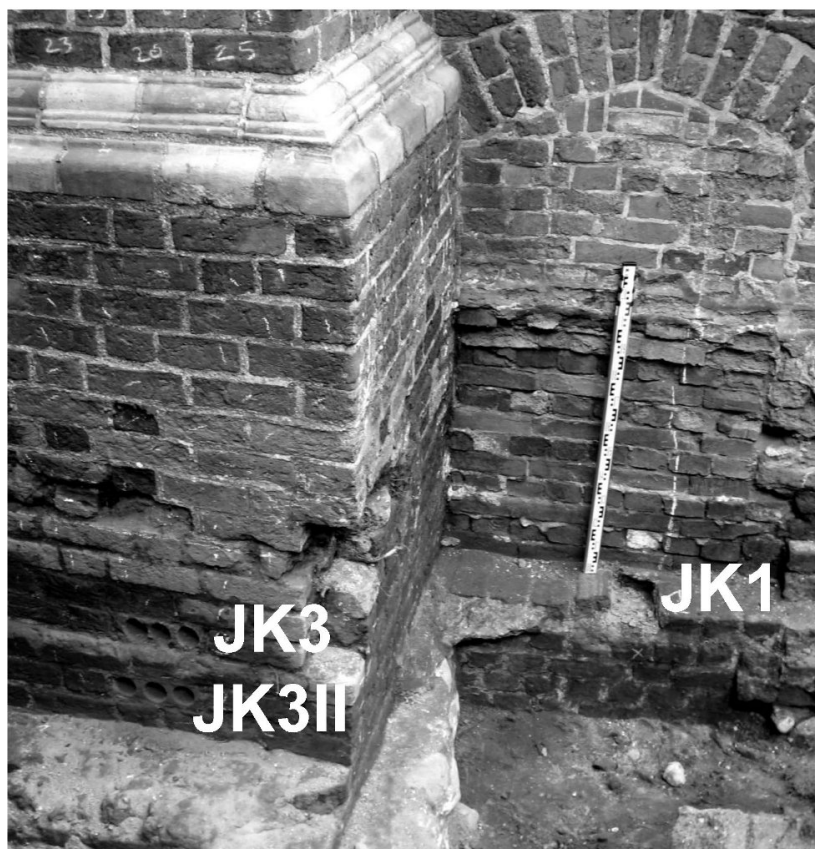

Fig. 4. The place of collecting the sample JK3. The discontinuity in the wall construction can be seen. Its presence complicates the geometry of the samples environment that has to be taken into account in estimating the $y$ component of annual dose. 
A. Chruścińska et al.

Table 1. Protocols used for the $\mathrm{D}_{\mathrm{e}}$ estimation.

\begin{tabular}{|c|c|c|c|}
\hline Step & Protocol: SAR OSL & Protocol: SAR TL & Protocol: Additive TL method \\
\hline 1 & $\begin{array}{l}\text { Excitation, regeneration dose } \\
\qquad D_{i}(i=0,1, . ., 4)^{1}\end{array}$ & $\begin{array}{l}\text { Excitation, regeneration dose } \\
\qquad D_{i}(i=0,1, \ldots, 4)^{2}\end{array}$ & $\begin{array}{l}\text { Excitation, additive dose } \\
\quad D_{i}(i=0,1, \ldots, 4)^{6}\end{array}$ \\
\hline 2 & Preheat for $10 \mathrm{~s}$ at $200-260^{\circ} \mathrm{C}^{3}$ & \multirow{2}{*}{$\begin{array}{l}\text { TL measurement, heating with the rate } \\
\text { of } 5 \mathrm{~K} / \mathrm{s} \text { to } 500^{\circ} \mathrm{C}+\text { background }\end{array}$} & \multirow{2}{*}{$\begin{array}{l}\text { TL measurement, heating with the rate of } 5 \mathrm{~K} / \mathrm{s} \text { to } \\
\qquad 500^{\circ} \mathrm{C}+\text { background }\end{array}$} \\
\hline 3 & Optical stimulation for $40 \mathrm{~s}$ at $125^{\circ} \mathrm{C}$ & & \\
\hline 4 & Excitation, test dose ${ }^{4}$ & Excitation, test dose 4 & Excitation, test dose 4 \\
\hline 5 & Preheat for $10 \mathrm{~s}$ at 220 or $260^{\circ} \mathrm{C}^{3}$ & \multirow{2}{*}{$\begin{array}{l}\text { TL measurement, heating with the rate } \\
\text { of } 5 \mathrm{~K} / \mathrm{s} \text { to } 500^{\circ} \mathrm{C}+\text { background }\end{array}$} & \multirow{2}{*}{$\begin{array}{l}\text { TL measurement, heating with the rate of } 5 \mathrm{~K} / \mathrm{s} \text { to } \\
\qquad 500^{\circ} \mathrm{C}+\text { background }{ }^{*}\end{array}$} \\
\hline 6 & Optical stimulation for $40 \mathrm{~s}$ at $125^{\circ} \mathrm{C}$ & & \\
\hline 7 & Optical stimulation for $40 \mathrm{~s}$ at $280^{\circ} \mathrm{C}^{5}$ & \multirow[t]{2}{*}{ Return to step 1 for the next cycle } & $\begin{array}{l}\text { Estimation of the correction for non-linearity } \\
\text { effects (new aliquots) }\end{array}$ \\
\hline 8 & Return to step 1 for the next cycle & & Heating with the rate of $5 \mathrm{~K} / \mathrm{s}$ to $500^{\circ} \mathrm{C}^{7}$ \\
\hline \multirow[t]{2}{*}{9} & & & $\begin{array}{l}\text { Excitation, regeneration dose } \\
\qquad D_{i}(i=1, \ldots, 4)^{8}\end{array}$ \\
\hline & & & $\begin{array}{l}\text { TL measurement, heating with the rate of } 5 \mathrm{~K} / \mathrm{s} \text { to } \\
\qquad 500^{\circ} \mathrm{C}+\text { background }\end{array}$ \\
\hline
\end{tabular}

${ }^{1}$ The following doses $D_{i}$ (in seconds of source opening time), depending on sample, for JKO-JK5: $D_{1}=75 \mathrm{~s} ; \mathrm{D}_{2}=50 \mathrm{~s}, \mathrm{D}_{3}=100 \mathrm{~s}, \mathrm{D}_{4}=75 \mathrm{~s}$; $\mathrm{D}_{0}=0 \mathrm{~s}$, in this cycle the natural OSL signal is measured.

${ }^{2}$ The following doses $D_{i}$, depending on sample, for JK1-JK5: $D_{1}=50 \mathrm{~s} ; \mathrm{D}_{2}=25 \mathrm{~s}, \mathrm{D}_{3}=75 \mathrm{~s}, \mathrm{D}_{4}=50 \mathrm{~s} ;$ for JK0: $\mathrm{D}_{1}=40 \mathrm{~s} ; \mathrm{D}_{2}=20 \mathrm{~s}, \mathrm{D}_{3}=60 \mathrm{~s}$, $\mathrm{D}_{4}=40 \mathrm{~s} ; \mathrm{D}_{0}=0 \mathrm{~s}$, in this cycle the natural TL signal is measured.

${ }^{3}$ Preaheat - the temperature was established individually for each sample by means of preheat test. JK0: $200^{\circ} \mathrm{C}, \mathrm{JK} 3: 240^{\circ} \mathrm{C}, \mathrm{JK} 1, \mathrm{JK} 4-5: 260^{\circ} \mathrm{C}$.

${ }^{4}$ Test dose depends on sample, it should not be higher than $50 \%$ of the highest dose $\mathrm{D}_{i}$. For all samples in SAR OSL the test dose is equal: $50 \mathrm{~s}$ and in SAR TL and Additive TL method is equal: $30 \mathrm{~s}$.

${ }^{5}$ This step is responsible for zeroing the OSL signal before the next cycle of protocol.

${ }^{6}$ The following doses $D_{i}$ were used for four groups of aliquots: $D_{1}=0 \mathrm{~s} ; D_{2}=20 \mathrm{~s}, \mathrm{D}_{3}=40 \mathrm{~s}, \mathrm{D}_{4}=60 \mathrm{~s}$;.

${ }^{7}$ This step is responsible for zeroing the TL signal.

${ }^{8}$ The following doses $D_{i}$ were used for four groups of aliquots: $D_{1}=20 \mathrm{~s} ; D_{2}=40 \mathrm{~s}, D_{3}=60 \mathrm{~s}, D_{4}=80 \mathrm{~s}$.

${ }^{*}$ The attempt to normalize the aliquots by the test dose (see comment in the text).

of TL signal integration. For samples JK1, JK3, JK4 the integration range was $360-400^{\circ} \mathrm{C}$, for sample JK5 320 $380^{\circ} \mathrm{C}$ and for sample JK0 $360-380^{\circ} \mathrm{C}$. The same integration ranges were used in both the TL SAR as well as the additive dose protocol. In the TL SAR protocol the recycling test made for all samples gave very good results. Whereas the SAR method allows the independent estimation of the $D_{\mathrm{e}}$ for the individual aliquots, the additive dose protocol requires measurements for a set of aliquots and therefore a kind of normalization is needed. Two methods of the normalization were tested: the massnormalization and the normalization by the TL measurement after a low normalization dose performed after the primary measurement used for the growth curve estimation. The mass-normalization is limited by the accuracy of weighing the aliquots, but the final $D_{\mathrm{e}}$ results in this case are comparative with results obtained by TL SAR protocol. The second method is not reliable because the TL signal after the normalization dose clearly correlates with the additive dose applied earlier for $D_{\mathrm{e}}$ estimation in the primary TL measurements (the pre-dose effect).

In the case of OSL measurements, for each sample a preheat test was performed for the temperatures from $160^{\circ} \mathrm{C}$ to $260^{\circ} \mathrm{C}$, every $20^{\circ} \mathrm{C}$ (Murray and Wintle, 2006). For samples JK0 the preheat temperature chosen from the plateau region was $200^{\circ} \mathrm{C}$, for JK $3-240^{\circ} \mathrm{C}$ and for JK1, $\mathrm{JK} 4, \mathrm{JK} 5-260^{\circ} \mathrm{C}$. The $40 \mathrm{~s}$ of bleaching at $280^{\circ} \mathrm{C}$ was applied after each measurement of OSL excited by the test dose. The recycling and recuperation tests were conducted as standard steps in SAR protocol (Murray and Wintle, 2006). Only these aliquots for which the recycling ratios fall within the range of acceptability 90 $110 \%$ were included in the final calculation of OSL $D_{\mathrm{e}}$. The recuperation was minimal.

\section{Annual Dose ( $D R$ ) estimation}

The results of gamma spectrometry are given as activities of the natural radionuclides that are present in the samples of bricks and soil (Table 2). These activities were used for calculating the total dose rates from the infinite matrix for the individual series $\left({ }^{238} \mathrm{U},{ }^{235} \mathrm{U}\right.$ and ${ }^{232} \mathrm{Th}$ ) and isotopes $\left({ }^{40} \mathrm{~K}\right.$ and $\left.{ }^{87} \mathrm{Rb}\right)$ (Guerin et al., 2011; Oczkowski et al., 2000). The ${ }^{87} \mathrm{Rb}$ dose rate is estimated as a part of the ${ }^{40} \mathrm{~K}$ dose rate assuming that the ${ }^{87} \mathrm{Rb} /{ }^{40} \mathrm{~K}$ activity ratio is 0.142 (Warren, 1978). On this basis annual dose $(D R)$ is calculated, taking into account information about the geometry of walls at the places of brick sampling, size of mineral grains, moisture effects, depth of the sample, etc. (Aitken, 1985; Oczkowski and Przegiętka 1998b). When the quartz inclusion technique is applied the contributions of $\beta$ and $\gamma$ radiation to the $D R$ have to be considered and it can be expressed by the following formula: 
$D R=\frac{D_{\beta, b r i c k}^{c a l}}{1+1.25 W_{b}}+\frac{D_{\gamma, \text { brick }}^{\text {cal }}}{1+1.14 W_{b}}+\frac{D_{\gamma, \text { soil }}^{\text {cal }}}{1+1.14 W_{s}}+D_{\text {cosmic rays }}$

where $D_{\beta, \text { brick }}^{\text {cal }}$ is the partial $\beta$ dose rate for brick, $D_{\gamma, \text { brick }}^{\text {cal }}$ is the partial $\gamma$ dose rate for brick and $D_{\gamma, \text { soil }}^{\text {cal }}$ the partial $\gamma$ dose rate for soil, index cal means the dose rates calculated on the basis of measurement data and the analysis of sample environment geometry (see below), $W_{\mathrm{b}}$ and $W_{\mathrm{s}}$ are the moisture contents in the brick and soil, respectively. They were measured directly after the sample collection and dependently on sample vary between 3 and $9 \%$.

The conditions of archaeological work by the St. James church did not allow using luminescence dosimetry for the estimation of the dose rate from gamma rays. The investigated deep foundations were available for about one week and only one time, so the installation of dosimetric capsules was not possible. In order to determine the annual dose from gamma rays, which have long ranges in brick and soil, specific geometry of the surroundings of bricks has to be taken into account. It concerns the dose contributions from the elements of sample surrounding, which exhibit different radioactivity, e.g. walls or layers of bricks or adjacent soil layers. In the presented investigations only the surroundings of the sample JK0 correspond to a simple situation with one boundary between two media having different radioactiv- ity (let us call it $1 / 2$ matrix geometry). All other samples required a more detailed consideration based on the principle of superposition. The partial gamma dose rates originating from brick and soil can be calculated by means of following expressions:

$$
\begin{aligned}
& D_{\gamma, \text { brick }}^{\text {cal }}=p_{T h}^{b} D_{\gamma, b, T h}^{\text {meas }}+p_{U}^{b} D_{\gamma, b, U}^{\text {meas }}+p_{K}^{b} D_{\gamma, b, K}^{\text {meas }} \\
& D_{\gamma, s \text { sol }}^{\text {cal }}=p_{T h}^{s} D_{\gamma, s, T h}^{\text {meas }}+p_{U}^{s} D_{\gamma, s, U}^{\text {meas }}+p_{K}^{s} D_{\gamma, s, K}^{\text {meas }}
\end{aligned}
$$

where index $b$ and $s$ means respectively brick and soil, index meas means the results (dose rates for the infinite matrix) obtained from gamma spectrometry for thorium series, uranium series $\left({ }^{238} U+{ }^{235} U\right)$ and potassium that are shown in Table 3, coefficients $p_{\mathrm{i}}$ are obtained from the analysis of sample surroundings.

Fig. 5 and Fig. 6 present the geometry cases that apply respectively to samples JK 1, JK $3(3 / 4$ brick matrix $+1 / 4$ soil matrix), JK5 ( $1 / 4$ brick matrix $+3 / 4$ soil matrix) and sample JK4 ( $3 / 8$ brick matrix $+5 / 8$ soil matrix). The spheres in these figures present the direct vicinity of the boundary between media having different radioactivities. The formulas for the coefficients $p_{\mathrm{i}}$ use coefficients determining the fractional doses for potassium as well as thorium and uranium series given by Aitken (Aitken, 1985, p. 290) for the radioactive soil adjacent to inert soil. The formulas for specific points, edges or planes are

Table 2. Activities of the natural radionuclides obtained by gamma spectrometry for the brick and soil samples.

\begin{tabular}{ccccc}
\hline Sample & \multicolumn{3}{c}{ ppm } & \\
\cline { 2 - 5 } & 232Th & 238 & ${ }^{435} \mathrm{~K}$ \\
\hline JK0 & $6.25 \pm 0.05$ & $1.72 \pm 0.02$ & $0.015 \pm 0.001$ & $1.69 \pm 0.04$ \\
\hline JK1 & $6.96 \pm 0.04$ & $2.15 \pm 0.02$ & $0.018 \pm 0.002$ & $1.52 \pm 0.03$ \\
\hline JK3 (brick I) & $6.02 \pm 0.03$ & $1.78 \pm 0.02$ & $0.020 \pm 0.001$ & $1.32 \pm 0.03$ \\
\hline JK3 (brick II) & $7.58 \pm 0.04$ & $2.19 \pm 0.02$ & $0.014 \pm 0.002$ & $1.63 \pm 0.03$ \\
\hline JK4 & $5.65 \pm 0.03$ & $1.69 \pm 0.02$ & $0.016 \pm 0.002$ & $1.34 \pm 0.03$ \\
\hline JK5 & $5.62 \pm 0.03$ & $1.56 \pm 0.02$ & $0.017 \pm 0.002$ & $1.35 \pm 0.03$ \\
\hline soil 0 (JK0) & $2.81 \pm 0.02$ & $0.82 \pm 0.01$ & $0.001 \pm 0.001$ & $1.26 \pm 0.07$ \\
\hline soil 1 (JK1, JK3) & $3.00 \pm 0.02$ & $0.81 \pm 0.01$ & $0.009 \pm 0.001$ & $1.20 \pm 0.02$ \\
\hline soil 2 (JK4, JK5) & $2.68 \pm 0.02$ & $0.72 \pm 0.01$ & $0.009 \pm 0.001$ & $1.23 \pm 0.02$ \\
\hline
\end{tabular}

Table 3. Data used for annual dose calculation $-\beta$ and $y$ dose rates for infinite matrix obtained from gamma spectrometry for thorium series, urani-

\begin{tabular}{|c|c|c|c|c|c|c|c|c|c|}
\hline \multirow{3}{*}{ Sample } & \multirow{3}{*}{$\begin{array}{l}\beta \text { dose } \\
(\mu \mathrm{G} / a)\end{array}$} & \multirow{3}{*}{$\begin{array}{c}\text { cosm. dose } \\
(\mu \mathrm{G} / \mathrm{a})\end{array}$} & \multicolumn{7}{|c|}{ Data for $y$ dose calculations } \\
\hline & & & \multicolumn{4}{|c|}{ brick } & \multicolumn{3}{|c|}{ soil } \\
\hline & & & $\begin{array}{l}D_{\gamma, b, T h}^{\text {meas }} \\
(\mu \mathrm{G} / \mathrm{a})\end{array}$ & $\begin{array}{l}D_{\gamma, b, U}^{\text {meas }} \\
(\mu G / a)\end{array}$ & $\begin{array}{l}D_{\gamma, b, K}^{\text {meas }} \\
(\mu \mathrm{G} / \mathrm{a})\end{array}$ & $W_{b} F_{b}$ & $\begin{array}{l}D_{\gamma, s, s h}^{\text {meas }} \\
(\mu G / a)\end{array}$ & $\begin{array}{c}D_{\gamma, s, U}^{\text {meas }} \\
(\mu \mathrm{G} / \mathrm{a})\end{array}$ & $\begin{array}{c}D_{\gamma, s, K}^{m e a s} \\
(\mu \mathrm{G} / \mathrm{a}) \\
\end{array}$ \\
\hline JKO & $1580 \pm 28$ & $53 \pm 13$ & $299.6 \pm 2.2$ & $194.0 \pm 2.0$ & $351.8 \pm 7.2$ & 0.09 & $135 \pm 1$ & $90.3 \pm 1$ & $263 \pm 14$ \\
\hline JK1 & $1552 \pm 19$ & $140 \pm 30$ & $333.4 \pm 1.5$ & $242.5 \pm 1.6$ & $317.9 \pm 4.8$ & 0.07 & $144 \pm 1$ & $91.5 \pm 1$ & $249 \pm 4$ \\
\hline JK3 (brick I) & $1334 \pm 17$ & $93 \pm 23$ & $288.8 \pm 1.4$ & $202.0 \pm 1.5$ & $275.2 \pm 4.2$ & 0.04 & $144 \pm 1$ & $91.5 \pm 1$ & $249 \pm 4$ \\
\hline JK3 (brick II)* & - & $\begin{array}{c}- \\
\end{array}$ & $363.4 \pm 1.7$ & $245.1 \pm 1.8$ & $338.9 \pm 5.1$ & 0.04 & - & - & - \\
\hline JK4 & $1319 \pm 17$ & $69 \pm 17$ & $271.0 \pm 1.5$ & $190.5 \pm 1.6$ & $278.5 \pm 4.3$ & 0.08 & $129 \pm 1$ & $81.8 \pm 1$ & $257 \pm 4$ \\
\hline JK5 & $1312 \pm 17$ & $75 \pm 18$ & $269.6 \pm 1.4$ & $176.8 \pm 1.5$ & $282.1 \pm 4.3$ & 0.09 & $129 \pm 1$ & $81.8 \pm 1$ & $257 \pm 4$ \\
\hline
\end{tabular}
um series and potassium for brick and soil samples, cosmic rays dose rate and brick moisture content.

* - The results of gamma spectrometry for the sample JK3 (brick II) were used for calculation the y dose rate for the sample JK3 (see details in the text). 

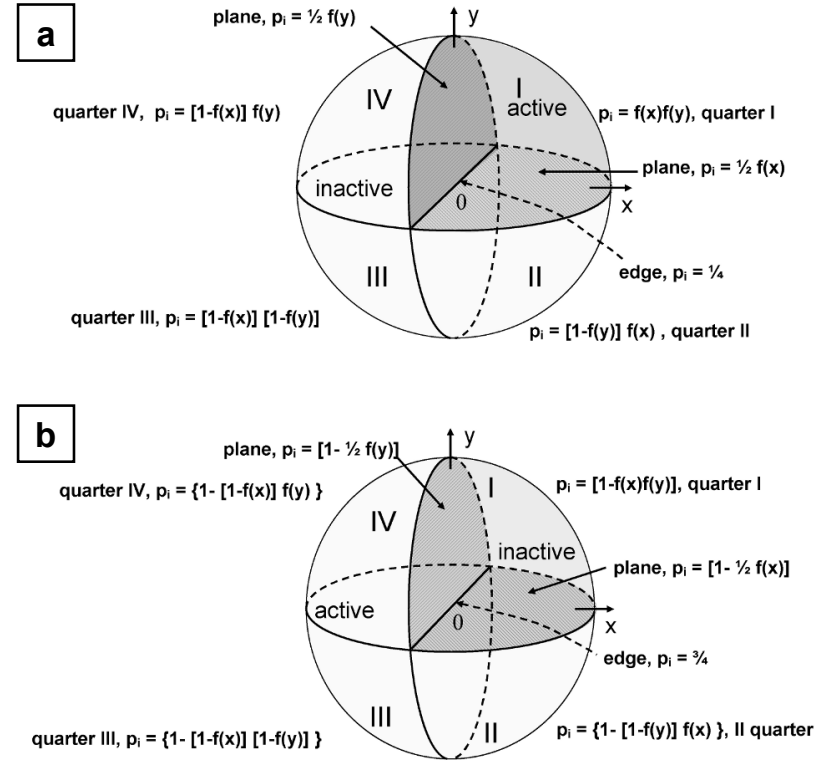

Fig. 5. Diagrams showing the geometry of surroundings for the samples JK3 and JK5 ("1/4 brick matrix + 3/4 soil matrix" geometry) together with the formulas for the coefficients $\mathrm{p}_{\mathrm{i}}$ that are used for calculating the annual $y$ dose from the brick and soil. (a) - one quarter is active and three quarters are inactive (case for the $y$ dose rate from brick); (b) - one quarter is inactive and three quarters are active (case for the $y$ dose rate from soil).
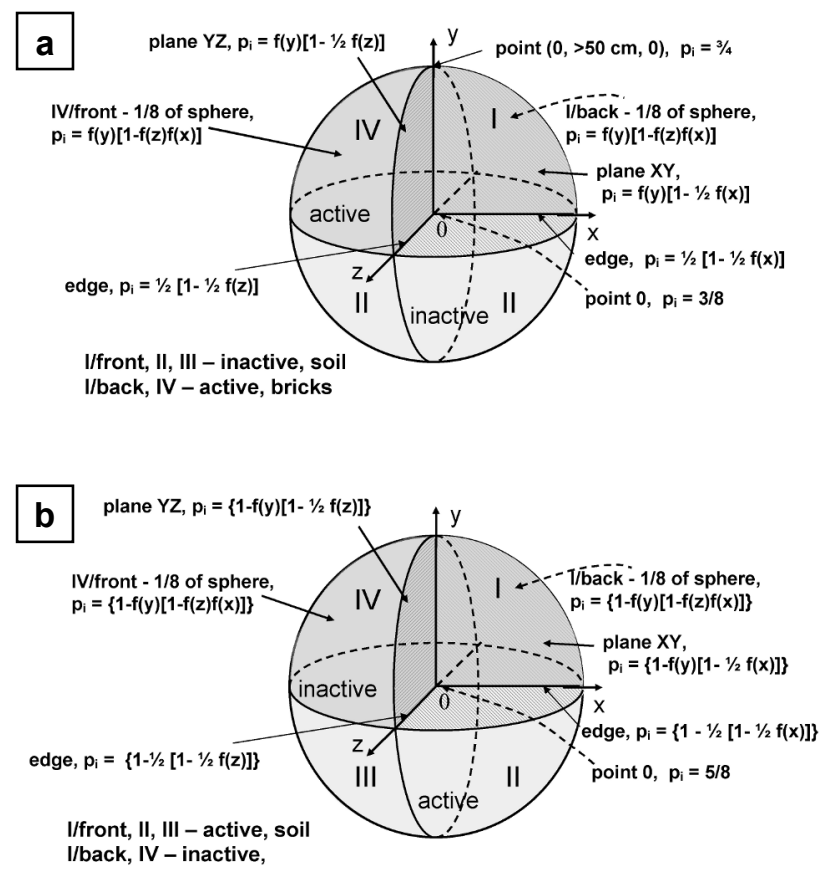

Fig. 6. Diagrams showing the geometry of surroundings for the sample JK4 ("3/8 brick matrix $+5 / 8$ soil matrix" geometry) together with the formulas for the coefficients $p_{i}$ that are needed for estimating the annual $y$ dose from the brick and soil. (a) - $3 / 8$ of matrix is active and $5 / 8$ of matrix is inactive (case for the $y$ dose rate from brick); (b) - 3/8 of matrix is inactive and $5 / 8$ of matrix is active (case for the $y$ dose rate from soil). shown in order to make easier the analysis of expressions given for the defined areas. These last can be straightforwardly reduced to the simple forms for points, edges or planes by substituting the adequate spatial coordinate values.

The geometry of surroundings of the samples JK3, which is especially complex, is presented in details in Fig. 7. This sample was taken above a slight plinth that arose from a discontinuity in the construction of the wall (Fig. 4). Additional cores of brick were taken below the plinth for gamma spectrometry measurements. A significant difference between the radioactivities of bricks above and below the plinth confirms the discontinuity in the wall construction and complicates the calculation of the gamma dose rate. The surroundings of sample JK3 has to be divided into three parts (two $1 / 4$ brick matrices and one $1 / 2$ soil matrix) that contribute to the total gamma dose rate. The formulas that arise from the study of the surroundings geometry for all samples and that have been used for the estimation of the partial gamma dose rates are presented in Table 4 together with the sample distances from the surfaces of different media.

A special case of the $D R$ estimation is the sample JK1 that has been taken from the still in the former entrance to the sacristy. Dating of this sample was supposed to help in establishing the period when this entrance was created. It was bricked up, but, unfortunately, there are no historical data concerning the time when it happened. Taking into account that the dominant part of $D R$ originates from beta rays, and that this part can be quite precisely established by the gamma spectrometry, an attempt was made to estimate the date of manufacturing the brick JK1. Two extreme cases of gamma dose rate were used for establishing the data limits. The highest gamma dose rate corresponds to a situation when the brick were a part of the doorstep in the sacristy entrance all the time until now and it were exposed to gamma rays from all the walls

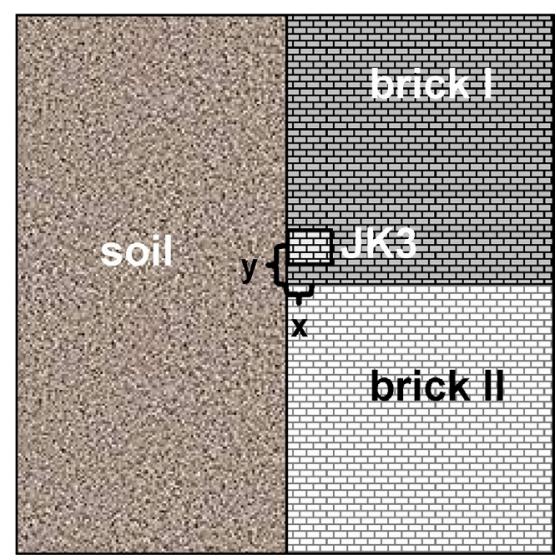

Fig. 7. The surroundings of the sample JK3. The bricks below the plinth in the wall construction have significantly higher radioactivity than bricks above. Three areas of different radioactivity had to be considered. 
Table 4. Formulas resulting from the analysis of the geometry of a brick environment used to determine the gamma dose rates for the individual samples.

\begin{tabular}{|c|c|c|}
\hline sample & $p_{b, l^{*}}$ & $p_{s, i}$ \\
\hline JKO (1/2) & $f_{i}(x), x=7.5$ & $1-f_{i}(x), x=7.5$ \\
\hline $\mathrm{JK} 1_{\max }$ & $\begin{array}{c}1-\left[1-f_{i}(x)\right]\left[1-f_{i}(y)\right], \text { (Fig. 5b, q. III) } \\
x=7.5, y=0\end{array}$ & $\begin{array}{c}{\left[1-f_{i}(x)\right]\left[1-f_{i}(y)\right],(\text { Fig. 5a, q. III) }} \\
x=7.5, y=0 ;\end{array}$ \\
\hline $\mathrm{JK} 1_{\text {min }}$ & $\begin{array}{c}f_{i}(x) f_{i}(y),(\text { Fig. 5a, q. I) } \\
x=7.5, y=0\end{array}$ & $\begin{array}{c}1-f_{i}(x) f_{i}(y),(\text { Fig. } 5 b, q . I) \\
x=7.5, y=0 ;\end{array}$ \\
\hline JK3 & $\begin{array}{c}f_{i}(x) f_{i}(y),(\text { Fig. } 7, \text { brick I active) } \\
{\left[1-f_{i}(y)\right] f_{i}(x),(\text { Fig. } 7, \text { brick II active })} \\
x=3.5, y=4\end{array}$ & $\begin{array}{c}1-f_{i}(x),(\text { Fig. } 7, \text { soil active }) \\
x=3.5\end{array}$ \\
\hline JK4 (1/8) & $\begin{array}{c}f_{i}(y)\left[1-f_{i}(z) f_{i}(x)\right], \text { (Fig. 6a, part IV/front) } \\
x=8, y=5, z=7.5\end{array}$ & $\begin{array}{c}1-f_{i}(y)\left[1-f_{i}(z) f_{i}(x)\right], \text { (Fig. 6b, part IV/front) } \\
x=8, y=5, z=7.5 ;\end{array}$ \\
\hline JK5 (1/4) & $\begin{array}{c}f_{i}(x) f_{i}(y),(\text { Fig. 5a, q. I) } \\
x=4, y=8\end{array}$ & $\begin{array}{c}1-f_{i}(x) f_{i}(y),(\text { Fig. 5b, q. I) } \\
x=4, y=8\end{array}$ \\
\hline
\end{tabular}

"Distances from the surfaces of different media $(x, y, z)$ are given in $\mathrm{cm}$.

around $(3 / 4$ matrix of the brick with radioactivity characteristic for sample JK1) and from the $1 / 4$ matrix of the adjacent soil (see $\mathrm{JK} 1_{\max }$ in Table 4 and Table 5 ). The lowest gamma dose rate may be approximated by a case when the sacristy entrance were bricked up already in the middle ages and the bricks were almost all the time covered by a soil layer enough thick in order to cut off the gamma rays originated from the church walls $(1 / 4$ matrix of the brick with radioactivity characteristic for sample $\mathrm{JK} 1$ and $3 / 4$ matrix of the adjacent soil, see $\mathrm{JK} 1_{\text {min }}$ in Table 4 and Table 5 ). It is worth noting that the soil collected at the church is significantly less radioactive than the bricks (see Table 2).

Another circumstance that should be taken into account in the dose rate estimation is the presence of mortar. In this case the mortar is about $22 \%$ of the wall volume and it has significantly lower radioactivity. As it was shown earlier, however, similar mortar content (radioactivity not lower than 0.5 of brick radioactivity) can influence the age rather in minor range (uncertainty of $\sim 1 \%$ ) (Chruścińska et al., 2008).

Table 5. Dating results for the bricks from the Saint James Church obtained by OSL SAR method.

\begin{tabular}{|c|c|c|c|c|}
\hline Sample & $\mathrm{De}_{\mathrm{e}}(\mathrm{mGy})$ & DR $(\mu \mathrm{G} / \mathrm{a})$ & Age (a) & Date $^{a}$ \\
\hline JKO & $1545 \pm 10$ & $2033 \pm 38$ & $760 \pm 46(19)^{*}$ & $1205-1297$ \\
\hline $\mathrm{JK} 1_{\max }$ & $1435 \pm 10$ & $2207 \pm 54$ & $650 \pm 39(20)^{*}$ & \multirow{2}{*}{$1240-1400^{* *}$} \\
\hline $\mathrm{JK} 1_{\min }$ & $1435 \pm 10$ & $1965 \pm 50$ & $730 \pm 41(23)^{*}$ & \\
\hline JK3 & $1359 \pm 20$ & $1911 \pm 30$ & $711 \pm 37(19)^{*}$ & $1263-1337$ \\
\hline JK4 & $1311 \pm 19$ & $1568 \pm 26$ & $836 \pm 46(23)^{*}$ & 1129 \\
\hline JK5 & $1336 \pm 14$ & $1682 \pm 27$ & $795 \pm 46(20)^{*}$ & $1170-1262$ \\
\hline $\begin{array}{l}\text { - cale } \\
\text { ollection } \\
\text { - the st } \\
\text { - the } 10\end{array}$ & $\begin{array}{l}\text { Jar ages } \\
2011 ; \\
\text { tical erro }\end{array}$ & re calcu & from the & r of samp \\
\hline
\end{tabular}

\section{RESULTS AND DISCUSSION}

Fig. 8 presents the equivalent dose values estimated by the TL and OSL measurements. As can be seen the TL $D_{\text {e }}$ values obtained for each sample by the both TL methods agree with each other quite well but the $D_{\mathrm{e}}$ estimated by the TL and OSL measurements diverge from each other significantly. Moreover, the differences between the OSL and TL results do not show any regularity, just as it has been also observed previously by Blain (Blain et al., 2010). The reason of this discrepancy is not clear at this stage of investigation but it is clear that the OSL $D_{\mathrm{e}}$ values should be taken for age calculation. The big difference between the TL $D_{\mathrm{e}}$ values of the particular samples ( $D_{\mathrm{e}}$ for sample JK0 equals about $3 D_{\mathrm{e}}$ for sample JK3) calls into question the credibility of these results. It is worth noting that the youngest bricks from the investigated set of samples (JK3) should be not much younger than

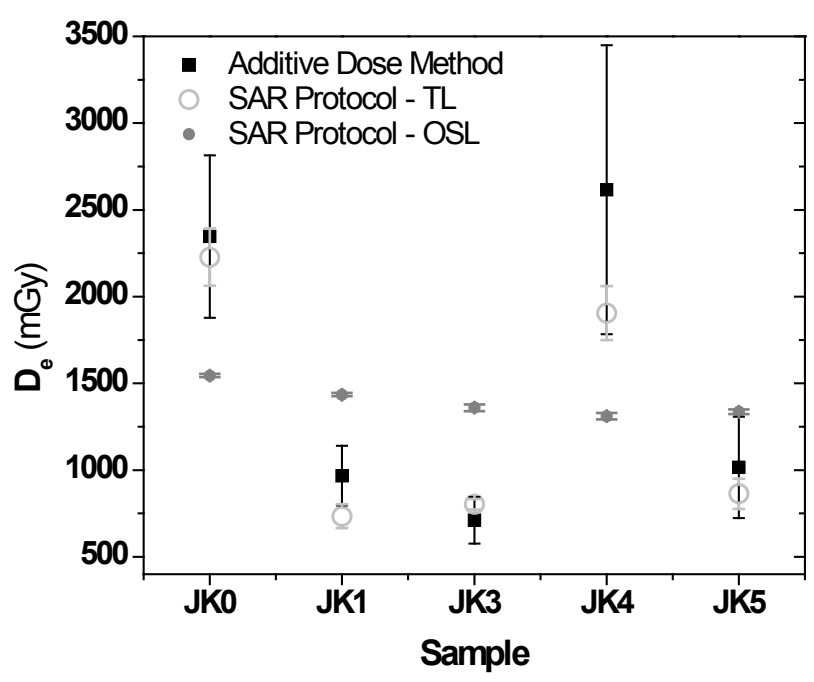

Fig. 8. The equivalent dose values estimated by three different methods. 
about 700 years what means that the oldest brick (JK0) could be about 2100 years old, what is impossible. The rather small differences between the OSL results are consistent with expectations that arise from the history of the site.

The ages and calendar dates that were calculated using the OSL $D_{\mathrm{e}}$ are presented in Table 5. The measurement overall uncertainties, shown in Table 5, were determined taking into account statistic (type A) and systematic (type B) errors. The last includes the uncertainty of the source calibration (about 2\%), the uncertainty in the parameters used for dose rate calculations (for beta and gamma attenuation, about $2-3 \%$ ) as well as the $20 \%$ uncertainty of moisture content. The total systematic errors were calculated accordingly to the suggestions in (Aitken, 1985). In Table 5 the statistic errors are presented in brackets.

The ages of bricks JK1 and, especially, JK3 correlate clearly with the time of constructing the present church that is known from historical documentary records. The start of the church building falls on the beginning of the $14^{\text {th }}$ century. The age range for sample JK1 allows to suppose that the bricked up entrance to the sacristy was the original ones, which was created during the construction of the presbytery.

Results for the rest of samples indicate that they come from an earlier period, what suggests that the foundation under the second aslant buttress was built earlier than the walls of the present church. Sample JK4 is the oldest and comes from the bottom of the foundation, which runs differently than the upper wall of the church and the buttress (Fig. 3). The overall uncertainties of the presented results do not allow to declare that the sample JK5 and JK0 are younger than sample JK4. According to the common opinion among historians of architecture beginning of the production of bricks on Polish territory falls at the beginning of the $13^{\text {th }}$ century. If so, one should suppose that the upper part of the range of data for sample JK4 obtained by dating is more reliable and therefore one can think that the bricks JK4, JK5 and JK0 were produced at the same time and that they are associated with the time of building the monastery. It is noteworthy that that the result obtained for sample JK0 (1205-1297 A.D.) narrows the range of age that was obtained for the investigated foundation of monastery by radiocarbon method (1210-1390 A.D.).

\section{CONCLUSIONS}

The TL and OSL methods have been applied for equivalent dose determination for bricks collected from the Saint James Church in Torun. Results obtained by additive dose method and TL SAR method agree with each other quite well but they both differ significantly from OSL results. These last lead to ages that are consistent with the historical knowledge about the investigated place. Although the easiest explanation of the discrep- ancy between the TL and OSL results could be the changes of the quartz sensitivity during the TL protocols, one should state that the actual cause is not clear in this particular case.

Due to the complex geometry of the brick surroundings a special attention was paid to estimating the gamma dose rate. Details of the way of calculating this part of annual dose were presented for individual samples.

Finally, the brick samples have been dated using the OSL SAR protocol. Historical records confirm the results obtained for the sample JK3, that were collected from the wall clearly associated with the construction of the presently existing church. The samples originating from the lower part of the foundations of the church and monastery turn out to be older what shows that before the standing church an earlier brick building existed at the same place.

\section{ACKNOWLEDGEMENTS}

This work has been financially supported by the grant No. 1137-F obtained from Nicolaus Copernicus University.

\section{REFERENCES}

Aitken MJ, 1985. Thermoluminescence Dating. Academic Press. London.

Bailiff IK, 1995. The use of ceramics for retrospective dosimetry in the Chernobyl exclusion zone. Radiation Measurements 24(4): 507511, DOI 10.1016/1350-4487(95)00020-F.

Bailiff IK, Bøtter-Jensen L, Correcher V, Delgado A, Göksu HY and Jungner H, 2000. Absorbed dose evaluations in retrospective dosimetry: methodological developments using quartz. Radiation Measurements 32(5-6): 609-613, DOI 10.1016/S13504487(00)00076-7.

Bailiff IK, 2007. Methodological developments in the luminescence dating of brick from English late-medieval and post-medieval buildings. Archaeometry 49(4): 827-851, DOI 10.1111/j.14754754.2007.00338.x.

Bevilacqua F, Chiavari C, Di Francesco C, Migliorini E, Martini M and Sibilia E, 1999. Thermoluminescence analysis in historical architecture: application to the ornamentations "in cotto" of the atrium of the Abbey of Pomposa. Sixth International Conference on Non Destructive Testing and Microanalysis for the Diagnostics and Conservation of the Cultural and Environmental Heritage, Roma, 17-20 May 1999.

Blain S, Guibert P, Bouvier A, Vieillevigne E, Bechtel F, Sapin C and Baylé M, 2007. TL-dating applied to building archaeology: The case of the medieval church Notre-Dame-Sous-Terre (Mont-SaintMichel, France). Radiation Measurements 42(9): 1483-1491, DOI 10.1016/j.radmeas.2007.07.015.

Blain S, Bailiff IK, Guibert P, Bouvier A and Baylé M, 2010. An intercomparison study of luminescence dating protocols and techniques applied to medieval brick samples from Normandy (France). Quaternary Geochronology 5(2-3): 311-316, DOI 10.1016/j.quageo.2009.02.016.

Blain S, Guibert P, Prigent D, Lanos P, Oberlin C, Sapin C, Bouvier A and Dufresne P, 2011. Combined dating methods applied to building archaeology: The contribution of thermoluminescence to the case of the bell tower of st Martin's church, Angers (France). Geochronometria 38(1): 55-63, DOI 10.2478/s13386-011-0010-0.

Chruścińska A, Jesionowski B, Oczkowski HL and Przegiętka KR, 2008. Using the TL single-aliquot regenerative-dose protocol for the verification of the chronology of the Teutonic Order Castle in Malbork. Geochronometria 30: 61-67, DOI 10.2478/v10003-0080006-9. 
Cicha A, 2010. Nielatwe odkrywanie klasztoru toruńskich cysterekbenedyktynek. Forum Scientae Cisterciense. Przyszłośc badań nad historia $i$ kultura cysterska $w$ Polsce. (Not easy exploration of Torun Cisterician-Benedictine nunnery. The future of research on the history and culture of the Cistercians in Poland.), ed. Łużyniecka \& Galar. Wrocław. pp. 181-196 (in Polish).

Freymuth O, 1981. Untersuchungen zur mittelalterlichen Baugeschichte der Neuerstaedter Pfarrkiche St. Jakobi zu Thorn. Thorn: Konigin der Weichsel. (Studies on the history of medieval architecture of the St. James parish church in the New Town, Torun. Torun: Queen of the Vistula.) Jaehning \& Letkemann. Goettingen. (in German)

Goedicke C, Slusallek K and Kubelik M, 1981. Thermoluminescence dating in architectural history: Venetian villas. Journal of the Society of Architectural Historians 40(3): 203-217, DOI $10.2307 / 989694$.

Grogler N, Houtermans FG and Stauffer H, 1960. Ueber die Datierung von Keramik und Ziegel durch Thermolumineszenz. (About the dating of ceramics and brick by thermoluminescence). Helvetica Physica Acta 33: 595-596 (in German).

Guérin G, Mercier N and Adamiec G, 2011. Dose-rate conversion factors: update. Ancient TL 29: 5-8.

Guibert P, Bailiff IK, Blain S, Gueli AM, Martini M, Sibilia E, Stella G and Troja SO, 2009. Luminescence dating of architectural ceramics from an early medieval abbey: The St Philbert Intercomparison (Loire Atlantique, France). Radiation Measurements 44(5-6): 488-493, DOI 10.1016/j.radmeas.2009.06.006.

Hütt G, Brodski L, Bailiff IK, Göksu Y, Haskell E, Jungner H and Stoneham D, 1993. Accident Dosimetry Using Environmental Materials Collected from Regions Downwind of Chernobyl: A Preliminary Evaluation. Radiation Protection Dosimetry 47(1-4): 307-311.

Kennedy GC and Knopf L, 1960. Dating by thermoluminescence. Archaeology 13: 147-148.

Kluczwajd K, 2009. Kościół Św. Jakuba Apostoła w Toruniu. (Saint James' Church in Toruń). Toruńskie Wydawnictwo Diecezjalne. Torun. (in Polish)

Krantz-Domasławska L and Domasławski J, 2001. Kościół Świętego Jakuba w Toruniu. (Saint James' Church in Toruń). Towarzystwo Naukowe w Toruniu. Toruń. (in Polish)

Martini M and Sibilia E, 2001. Radiation in archaeometry: archaeologi- cal dating. Radiation Physics and Chemistry 61(3-6): 241-246, DOI 10.1016/S0969-806X(01)00247-X.

Murray AS and Wintle AG, 2006. A review of quartz optically stimulated luminescence characteristics and their relevance in singlealiquot regeneration dating protocol. Radiation Measurements 41(4): 369-391, DOI 10.1016/j.radmeas.2005.11.001.

Oczkowski HL and Przegiętka KR, 1998a. TL Dating of Young Aeolian Deposits from Kępa Kujawska. Radiation Measurements 29(3-4): 435-439, DOI 10.1016/S1350-4487(98)00025-0.

Oczkowski HL and Przegiettka K, 1998b. Partial matrix doses for thermoluminescence dating. Physica Scripta 58: 534-537, DOI 10.1088/0031-8949/58/5/019.

Oczkowski HL, Przegiętka KR, Lankauf KR and Szmańda JB, 2000. Gamma spectrometry in thermoluminescence dating, Geochronometria 18: 57-62.

Roque C, Guibert P, Vartanian E, Bechtel F, Treuil R, Darcque P Koukouli-Chryssanthaki H and Malamidou D, 2002. The Chronology of the neolithic sequence at Dikili Tash, Macedonia, Greece: TL dating of domestic ovens. Archaeometry 44(4): 613-633, DOI 10.1111/1475-4754.t01-1-00089.

Roque C, Guibert P, Duttine M, Vartanian E, Chapoulie R and Bechtel F, 2004. Dependence of luminescence characteristics of irradiated quartz with thermal treatment and consequences for TL-dating: Application to Dating of Solutrean heated quartz pebbles from Laugerie Haute (Dordogne, France). Geochronometria 23: 1-8.

Sulkowska-Tuszyńska K, 2010. Apud Terram, Ante Ecclesiam. Niezapisane karty historii kościoła i parafii św. Jakuba w Toruniu. (Unwritten episodes in the history of the parish and church of Saint James, Toruń). Pomerania Antiqua, t. 23, 249-254 (in Polish)

Sulkowska-Tuszyńska K, 2012. Kamienna misa chrzcielna odkryta przy kościele św. Jakuba w Toruniu. (A stone baptismal bowl discovered near the church of Saint James in Torun'), Slavia Antiqua, $\mathrm{t}$. LIII. Poznań 2012 (in Polish)

Sulkowska-Tuszyńska K and Anna Cicha A, 2010. Dawny klasztor przy kościele św. Jakuba w Toruniu i jego otoczenie w świetle badan archeologicznych $z$ lat 2008-2009. (The former convent near the Saint James Church in Torun and its surroundings in the light of archaeological research, in the years 2008-2009). Rocznik Toruński, t. 37, pp. 251-274. (in Polish)

Warren SE, 1978. Thermoluminescence dating of pottery: an assessment of the dose-rate from rubidium. Archaeometry 20(1): 71-72, DOI 10.1111/j.1475-4754.1978.tb00215.x. 